\title{
Experimental study of a macrocrack propagation in a concrete specimen subjected to creep loading
}

\author{
P. Rossi, C. Boulay, J-L. Tailhan, E. Martin \\ Institut Français des Sciences et Technologies des Transports, de l'Aménagement et des Réseaux \\ (IFSTTAR), Université Paris-Est, France
}

\begin{abstract}
Structures managers need a better prediction of the delayed failure of concrete structures, especially for very important structures like nuclear power plant encasement. Sustained loadings at high level (above $75 \%$ of loading capacity of the structure), can lead to structure failure after some time. In this study, a series of 4-point bending tests were performed in order to characterize the creep behaviour of pre-cracked beams under high load level. The specimens were made of normal strength concrete. A power law relationship is observed between the secondary deflection creep rate and the failure time. It is also shown that when crack propagation occurs during the creep loading, the creep deflection rate increases with the creep loading level and with the crack propagation rate.
\end{abstract}

\section{Introduction}

The delayed failure of concrete structures under sustained loading has been an important issue for researchers and structure managers for a long time. Among other topics, the progression to failure of a structure with a localized macrocrack subjected to a sustained loading needs a better understanding.

In the past some researchers worked on the interaction between crack propagation and time dependence behaviour of concrete [1-11].

The scientific objective of the present work is to understand the physical mechanisms involved in the possible coupling between crack propagation and delayed behaviour of concrete.

The industrial objective is more concerned with the case of the containment vessel of a nuclear power plant.

As regards nuclear civil engineering, safety requirements specify durability of then containment vessel functionalities in terms of stability and confinement. This requirement is very different from classical functionalities in buildings and can be very demanding.

In France, before the new European pressurized reactor (EPR), the reactor buildings of the latest PWR type consisted of two concentric containments structures (24 1300-1450 MWe reactors of this type are operated presently). The inner containment is made with concrete biaxially prestressed. It is $120 \mathrm{~cm}$ thick and without a metallic liner. It is designed to withstand an internal pressure of 0.53 MPa corresponding to a pressure due to the LOCA scenario (loss of cooling accident). The large thickness and prestressing help avoid cracking and large leakage in case of this accident.

To operate nuclear power plants (NPP), EDF (the French operator) must justify to the French safety authority the capability of the containment to ensure, in case of an accident, a leak rate lower 
than $1.5 \%$ per day of the total mass of fluids. To evaluate, this possible leak rate, experimentally, each containment structure undergoes every 10 years a leakage test at $0.53 \mathrm{MPa}$ in dry air and at atmospheric temperature (the duration of this leakage test is around 3 days). In this case the leak rate should not exceed $1 \%$ (in total). If it is not the case, repairs are needed to improve the tightness of the containment. Of course, these repairs in a nuclear context are very expensive and if the nuclear power plant is not allowed to operate, the losses are very important (about $1 \mathrm{M} €$ per day).

During this leakage test, existing cracks in the structure can propagate. So, it is very important to evaluate the cracking evolution.

\section{Concrete studied}

The mix design of the studied concrete is given in Table 1 .

Table 1. Concrete mix design

\begin{tabular}{|c|c|}
\hline Components & $\mathrm{kg} / \mathrm{m}^{3}$ \\
\hline $\begin{array}{c}\text { Cement : CEMI 52.5N PMES } \\
\text { CA2 }\end{array}$ & 340 \\
\hline Dried sand-lime aggregate 0/4 & 739.45 \\
\hline Dried sand-lime agregate $6.3 / 20$ & 1072.14 \\
\hline Added water & 184.22 \\
\hline
\end{tabular}

In order to evaluate the basic mechanical characteristics (compressive and tensile strengths) of the studied concrete, uniaxial tensile and compression tests were performed. Compression tests were carried out at different ages, 7, 14, 28, 64, 90, 180 days, to study the evolution of the concrete strength. For the uniaxial tension tests, 1 expiry at 64 days was taken into account. Six specimens per concrete age were tested both for compression and uniaxial tension tests. Table 2 summarizes the results obtained

Table 2. Concrete mechanical characteristics in static

\begin{tabular}{|c|c|c|c|c|c|c|c|}
\hline $\begin{array}{c}\text { Mechanical characteristic } \\
(\mathrm{MPa})\end{array}$ & \multicolumn{5}{|c|}{ Compression } & Tension \\
\hline Concrete age (days) & 7 & 14 & 28 & 64 & 90 & 180 & 64 \\
\hline Average value (MPa) & 31.2 & 35.1 & 39.9 & 42.2 & 44.4 & 51.2 & 2.8 \\
\hline
\end{tabular}

\section{Experimental program and set-ups}

This experimental study focuses on 4-point bending tests of one beam size: $200 \mathrm{~mm}$ height, $150 \mathrm{~mm}$ width and $700 \mathrm{~mm}$ face to face.

Twenty-four hours after casting, the specimens were demolded and protected from drying by two layers of an auto-adhesive aluminum and stored in a temperature and humidity controlled room.

The beams were bended under a 4-point loading, each point load spaced at $200 \mathrm{~mm}$.

The beams under high-creep load level were tested under a $100 \mathrm{kN}$ hydraulic testing machine. This set-up is also used for pre-cracking of beams and beam characterization. 
The beams are instrumented with two deflection measurements; one at mid-point and one under a load-point (see figure1). This apparatus is fixed at two points directly upon the lower bearings. This disposition ensures that there is no influence of bearing deformations on the measurements.

Another measurement system (LVDT) is used to evaluate the horizontal displacement (displacement parallel to the specimen length) at a certain level of the specimen width in the tensile zone. This measurement is made at $25 \mathrm{~mm}$ of the inferior fibre of the specimen (see figure 1). The measurement basis of this horizontal displacement, called in this work D25, is $200 \mathrm{~mm}$.

Concerning the static test for beam characterization, six specimens were tested. The concrete age when these specimens are loaded is 28 days.

Concerning the step related to the pre-cracking of the specimens, the strategy adopted is the following:

- From the bending stress versus deflection average curve (obtained with the static tests), a deflection value related to the post-peak behaviour is chosen. It is called $\delta_{0}$. This value corresponds to a certain length of macrocrack and to a certain value of loading force on the specimen, called $\mathrm{P}_{0}$.

- So, for the specimens which will be loaded in creep, the first step corresponds to a static loading until the deflection $\delta_{0}$.

After having created the initial crack, the specimen is unloaded. From this point, the specimen is reloaded until a force corresponding to a given percentage of $\mathrm{P}_{0}$. This force is called $\mathrm{P}_{\mathrm{S}}$ (Figure 2). The maximal duration of the creep loading on this machine does not exceed 3 days. After this duration, the test is stopped.

During the creep loading, unloading/reloading cycles are performed to follow the compliance evolution of the specimen (Figure 3). The objective is to determine eventual crack propagation during creep.

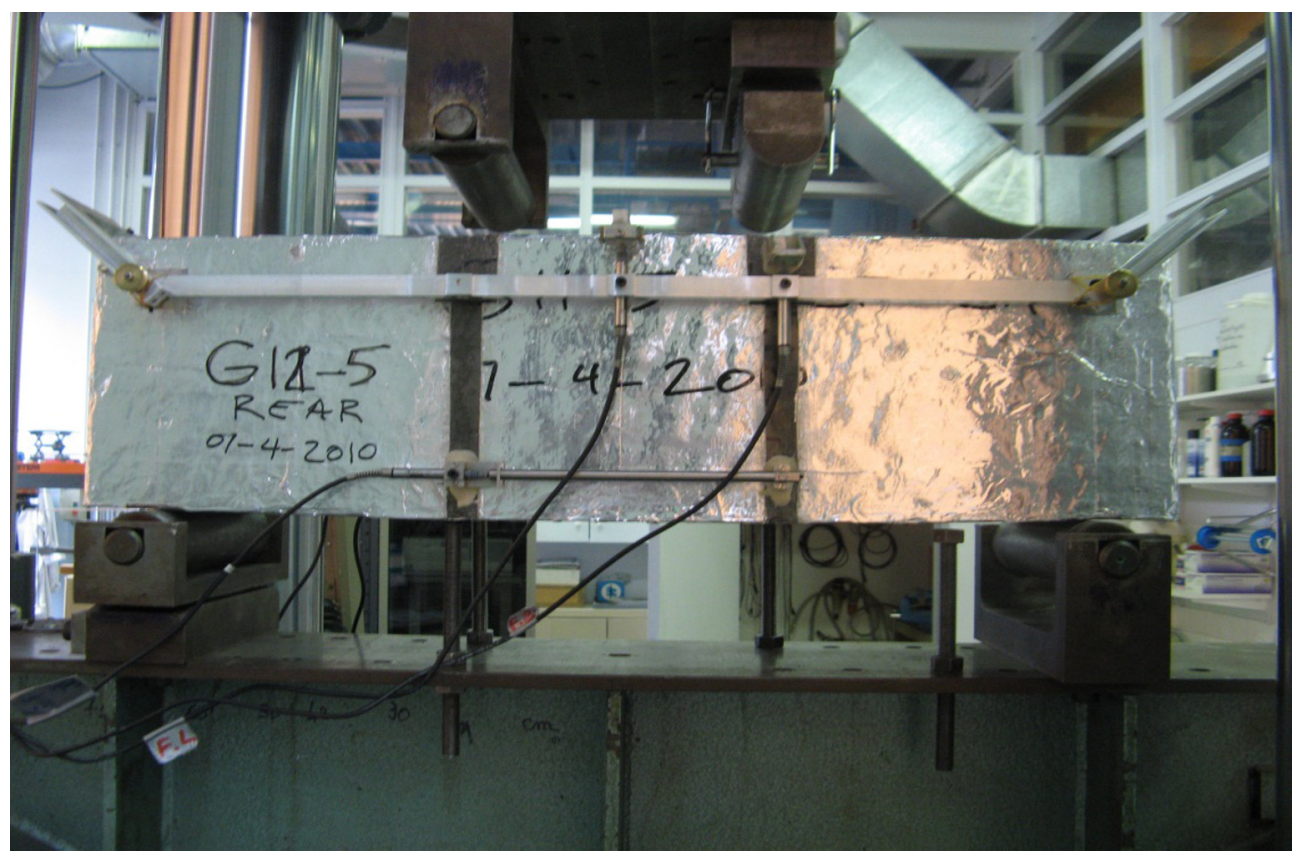

Fig.1. Test set-up for pre-cracking and high-load level creep tests 


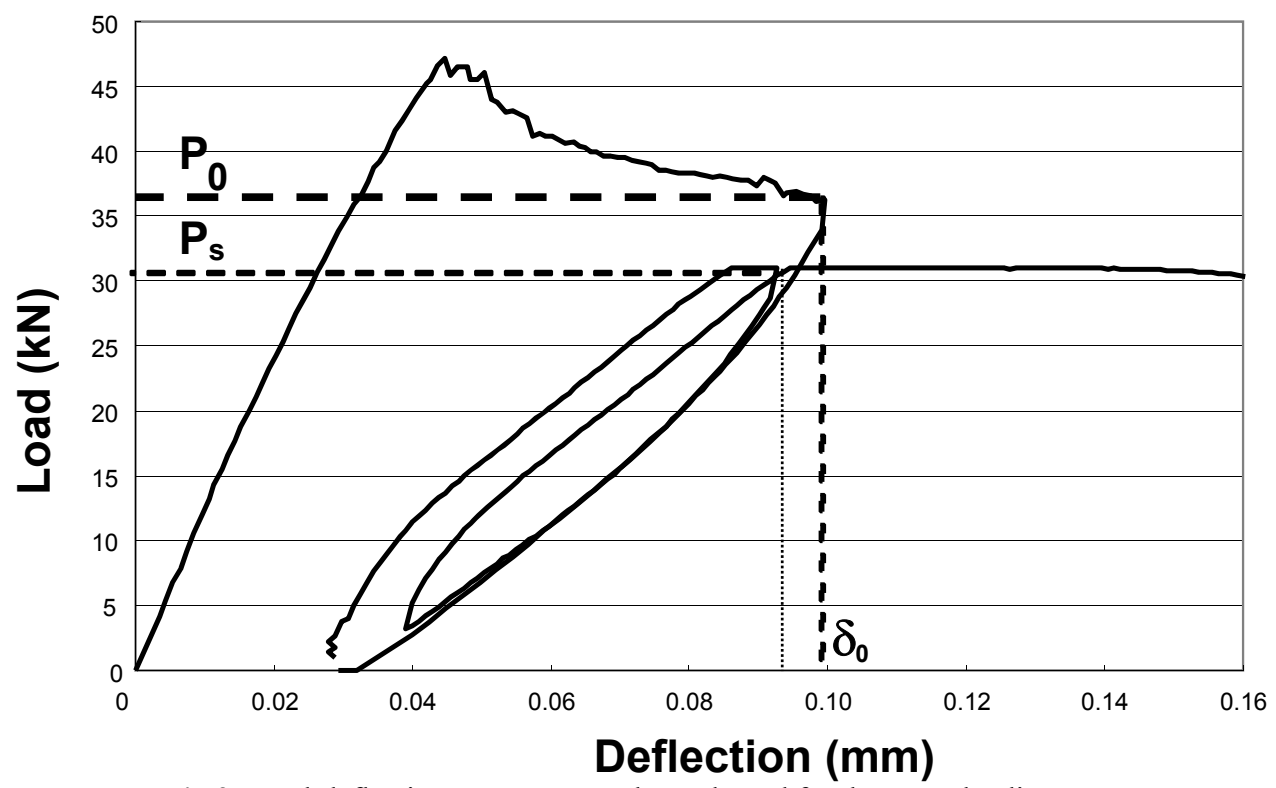

Fig.2. Load-deflection curve - Procedure adopted for the creep loading

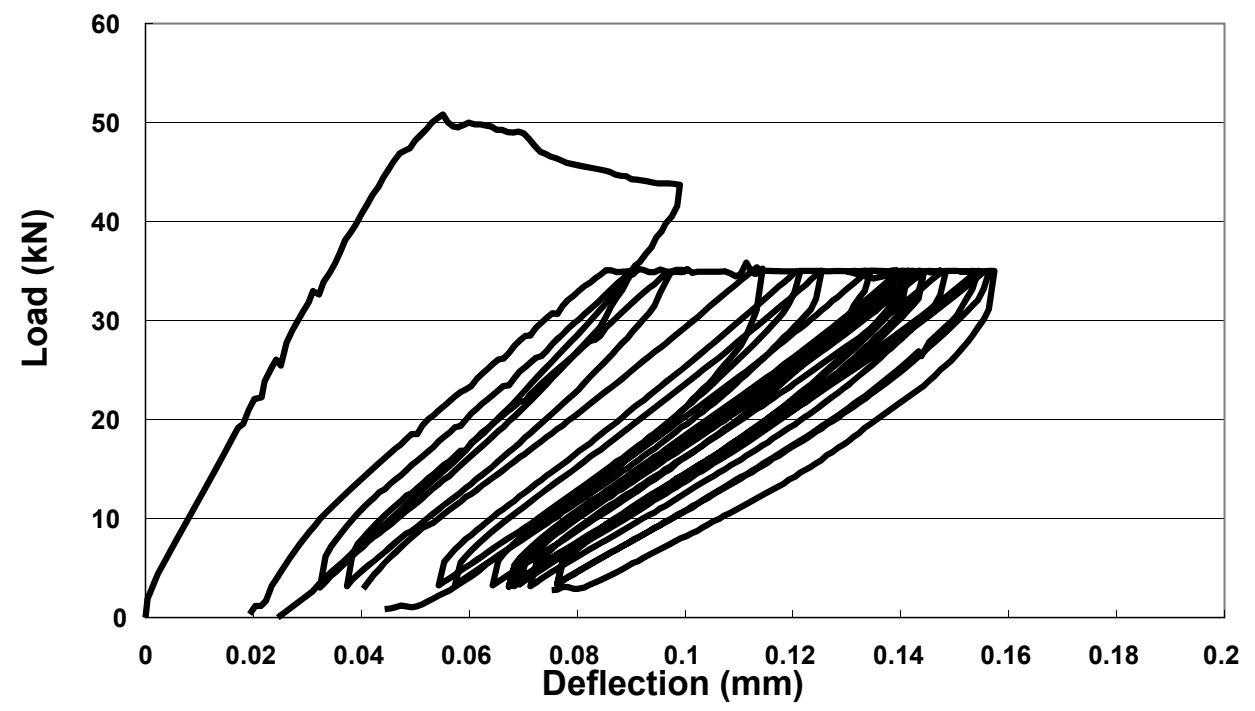

Fig. 3. Example of unloading/reloading procedure during the creep loading

\section{Experimental results}

In the Table 3, the concrete age at loading is presented with the load level, $\mathrm{P}_{\mathrm{S}} / \mathrm{P}_{0}$, and the deflection level (at mid-point) imposed before creep, $\delta_{\mathrm{S}}$. The time to failure is also indicated.

In figure 4 , the relation between the time to failure (in log scale) and the secondary deflection creep rate (in log scale) is presented. This secondary deflection creep rate is not available for all tests (see table 3) due to problems with the deflection measurement. 
Table 3. Series of bending creep test - Different results

\begin{tabular}{|c|c|c|c|c|c|c|}
\hline $\begin{array}{l}\text { Concrete } \\
\text { age } \\
\text { at loading } \\
\text { (days) }\end{array}$ & $\overline{\mathrm{P}_{\mathrm{S}} / \mathrm{P}_{0}}$ & $\begin{array}{c}\delta_{0} \\
(\mathrm{~mm})\end{array}$ & $\begin{array}{c}\text { Time to failure } \\
\text { (Seconds) }\end{array}$ & $\begin{array}{l}\text { Cycles } \\
\text { Yes/No- } \\
\text { Number }\end{array}$ & $\begin{array}{l}\text { Secondary } \\
\text { deflection } \\
\text { creep rate } \\
\left(\mathrm{x} 10^{-7} \mathrm{~mm} / \mathrm{s}\right.\end{array}$ & $\begin{array}{c}\text { Secondary } \\
\text { displacement } \\
\text { (D25) creep rate } \\
\left(\mathrm{x} 10^{-7} \mathrm{~mm} / \mathrm{s}\right)\end{array}$ \\
\hline 60 & 0,80 & 0,1 & $\begin{array}{c}\text { Stop of the test } \\
(80575)\end{array}$ & No & 1.7 & 1.7 \\
\hline 56 & 0,85 & 0,1 & 1852 & No & 119 & 151 \\
\hline 67 & 0,85 & 0,1 & 4400 & Yes - 4 & 75.9 & 86.5 \\
\hline 68 & 0,88 & 0,1 & 287 & No & 877 & 1070 \\
\hline 68 & 0,85 & 0,1 & 5750 & No & 66.5 & 80.7 \\
\hline 80 & 0,85 & 0,08 & 1874 & Yes - 3 & 142 & 231 \\
\hline 84 & 0,80 & 0,08 & 72716 & Yes - 6 & No & 2.7 \\
\hline 88 & 0,76 & 0,1 & \begin{tabular}{|c|} 
Stop of the test \\
$(252594)$
\end{tabular} & Yes - 8 & No & 0.311 \\
\hline 86 & 0,80 & 0,1 & 93713 & Yes - 12 & No & 6.15 \\
\hline 187 & 0,85 & 0,1 & 533 & No & 306 & 378 \\
\hline 189 & 0,84 & 0,1 & 590 & No & 190 & 225 \\
\hline
\end{tabular}

Figure 5 provides the curves of the compliance evolution during time. The compliance evolution is equal to $C(t)-C_{S}$ where $C(t)$ is the specimen compliance at time $t$ during the creep loading and $C_{S}$ is the specimen compliance just before the creep loading.

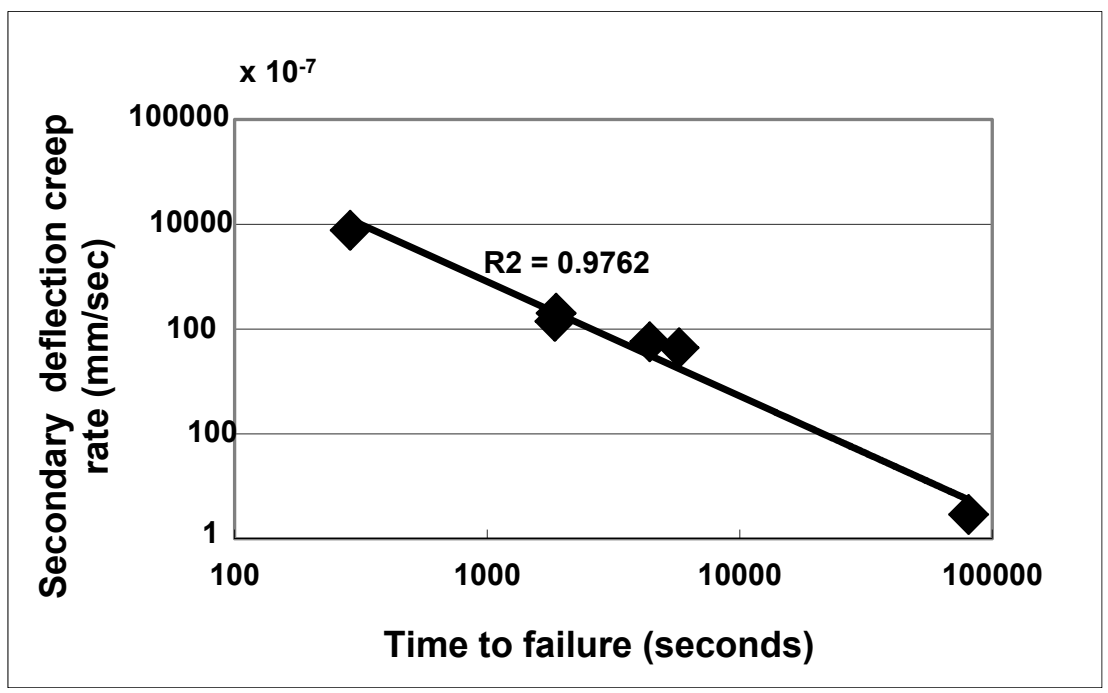

Fig. 4. Secondary deflection creep versus time to failure 


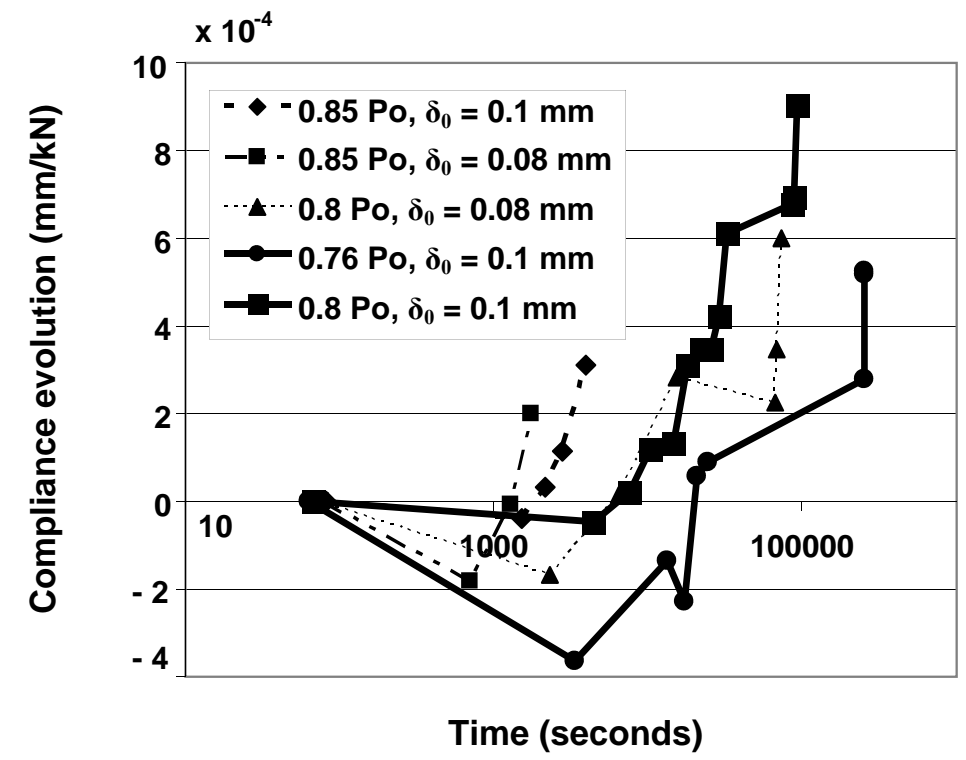

Fig. 5. Compliance evolution versus time

\section{Results analysis}

Figure 4 proves that there is a correlation between crack propagation and creep in concrete: the greater is the creep, the greater the crack propagation rate is.

A look of Figure 5 leads to the following remark: crack propagation (positive evolution of the compliance) always occurs after a negative evolution of the compliance.

Table 4 provides the relationship among the relative evolution rate, the creep loading level and the secondary displacement (D25) creep rate (The number of values related to the secondary deflection rate are not sufficient, see Table 3$)$. This relative evolution rate is given by $C(t)-C_{S} / C_{S}$.

Table 4. Relative evolution rate of the compliance

\begin{tabular}{|c|c|c|c|c|}
\hline $\mathrm{P}_{\mathrm{S}} / \mathrm{P}_{0}(\%)$ & 80 & 80 & 85 & 85 \\
\hline$\left[\left(\mathrm{C}(\mathrm{t})-\mathrm{C}_{\mathrm{S}}\right) / \mathrm{C}_{\mathrm{S}}\right] \mathrm{x} \mathrm{t}^{-1}$ & 0.02 & 0.03 & 0.5 & 1 \\
$\left(\mathrm{x} \mathrm{10} 0^{-4} \mathrm{~s}^{-1}\right)$ & 2.7 & 6.15 & 86.5 & 231 \\
\hline $\begin{array}{c}\text { Secondary } \\
\text { displacement (D25) } \\
\text { creep rate } \\
\left(\mathrm{x} \mathrm{10} 0^{-7} \mathrm{~mm} / \mathrm{s}\right)\end{array}$ & & & \\
\hline
\end{tabular}


Figures 6 and 7 the relative evolution rate of the compliance as a function of the creep loading level and as a function of the secondary displacement (D25) creep rate, respectively.

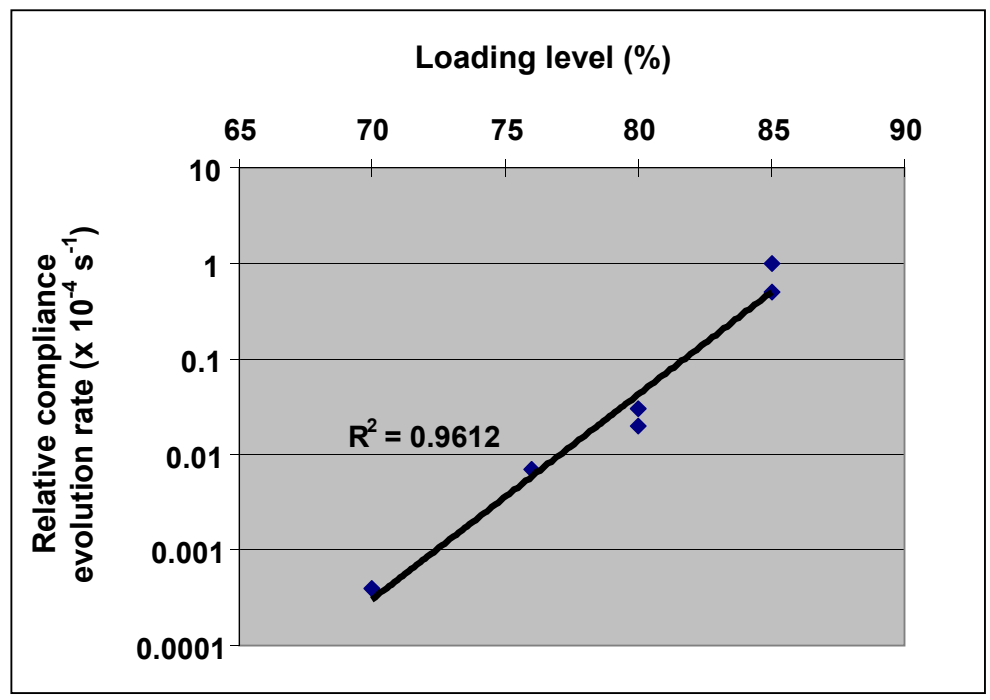

Fig. 6. Relative evolution of the compliance rate versus the creep loading

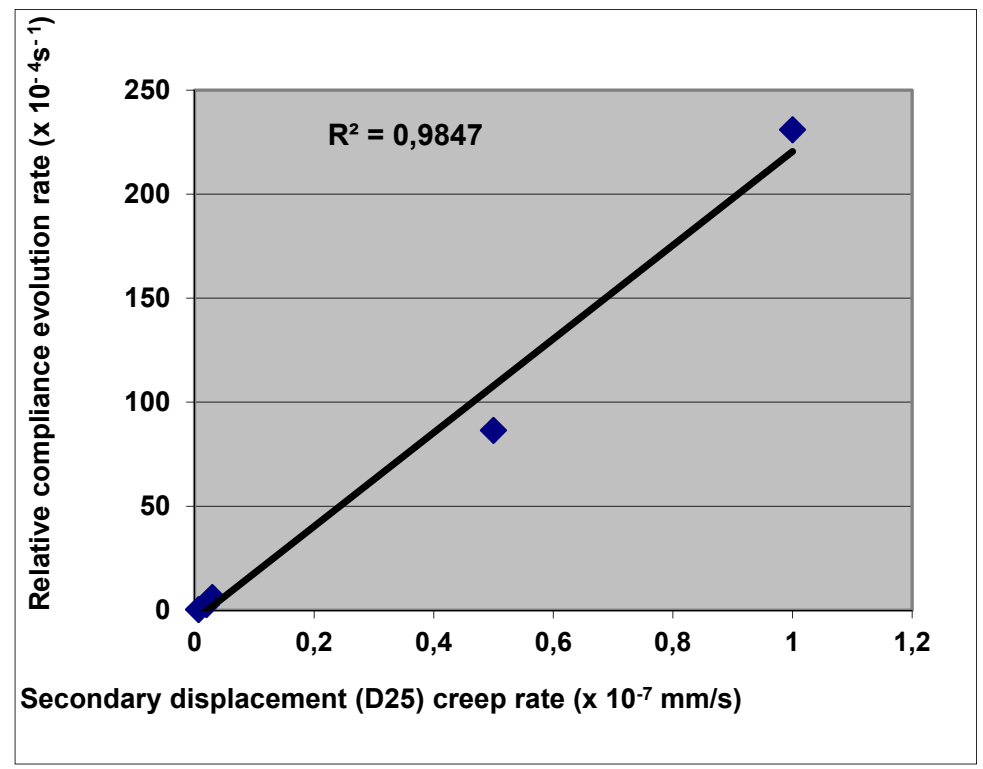

Fig. 7. Relative evolution of the compliance rate versus the secondary creep displacement (D25) rate

From Table 4 and figures 6 and 7, the following remarks can be made when the crack propagates continuously during the creep loading:

- the crack propagation rate (represented by the relative evolution rate of the compliance) increases with the creep loading level and

- the secondary displacement (D25) rate increases with the crack propagation rate. 
Concerning the continuous crack propagation occurring during the secondary creep step of the concrete specimen the following assumption could be proposed: during a creep loading (a constant loading during time) the secondary creep of the concrete specimen is the consequence of stable crack propagation. In others words, the stable crack propagation is the driving force for the secondary creep of the cracked specimen

\section{Acknowledgements}

The authors wish to acknowledge the financial support from EDF R\&D.

\section{References}

1. P. Rossi, "Coupling between the crack propagation velocity and the vapour diffusion in concrete", Materials and Structures, vol.22, pp. 91-97, 1989.

2. P. Rossi, C. Boulay, "Influence of free water in concrete on the cracking process", Magazine of Concrete Research, V. 42, No. 152, pp. 143-146, 1990.

3. E. Denarié, C. Cécot, C. Huet, "Characterization of creep and crack growth interactions in fracture behavior of concrete", Cement and Concrete Research, 36, 571-575, 2006.

4. Dénarié, "Etude expérimentale des couplages viscoélasticité-croissance des fissures dans les bétons de ciment, Doctoral Thesis no. 2195, Swiss Federal Institute of Technology, Lausanne, 2000.

5. H. Rüsch, "Researches toward a general flexural theory for structural concrete", ACI Journal, Proceedings, Vol. 57, p. 1-28, July 1960.

6. M.M. Smadi, F.O. Slate, A.H. Nilson, "High-, medium-, and low-strength concretes subject to sustained overloads- strains, strengths, and failure mechanisms, ACI Journal, 657-664, 1985.

7. C. Mazzotti, M. Savoia, "Nonlinear creep, Poisson's ratio, and creep-damage interaction of concrete in compression", ACI Materials Journal, v.99, no.5, September-October 2002.

8. Z.P. Bazant, R.Gettu, "Rate effects and load relaxation in static fracture of concrete", ACI Materials Journal, 89, no.5, September-October 1992.

9. F.P. Zhou, "Time-Dependent Crack Growth and Fracture in Concrete", Ph.D. Thesis, TVBM1011, University of Lund, Sweden, 1992.

10. Carpinteri, S.Valente, F.P.Zhou, G.Ferrara, G. Melchiorri, "Tensile and flexural creep rupture tests on partially-damaged concrete specimens", Materials and Structures, Vol.30, pp. 269-276, June 1997,

11. M. Omar et al., Creep-damage coupled effects: experimental investigation on bending beams with various sizes, Journal of Materials in Engineering, ASCE, 21, 65, 2009. 